Acknowledgments: Professor David Yu

Disclosure of Interests: Qing Han: None declared, Zhaohui Zheng: None declared, Kui Zhang: None declared, Zheng Yu: None declared, Fengfan Yang: None declared, Qiang Liang: None declared, Ping Zhu: None declared, Xenofon Baraliakos Grant/research support from: Grant/research support from: AbbVie, BMS, Celgene, Chugai, Merck, Novartis, Pfizer, UCB and Werfen, Consultant of: AbbVie, BMS, Celgene, Chugai, Merck, Novartis, Pfizer, UCB and Werfen, Speakers bureau: AbbVie, BMS, Celgene, Chugai, Merck, Novartis, Pfizer, UCB and Werfen

DOI: 10.1136/annrheumdis-2020-eular.2798

\section{THU0527 1 FREQUENCY AND ANATOMIC DISTRIBUTION OF MAGNETIC RESONANCE IMAGING LESIONS IN THE SACRO-ILIAC JOINTS OF HEALTHY SUBJECTS AND PATIENTS WITH SPONDYLOARTHRITIS}

S. Hecquet ${ }^{1}$, J. P. Lustig ${ }^{2}$, F. Verhoeven ${ }^{1}$, M. Chouk ${ }^{1}$, S. Aubry ${ }^{2}$, D. Wendling ${ }^{1}$, C. Prati ${ }^{1} .{ }^{1}$ University Hospital, Rheumatology, Besançon, France; ${ }^{2}$ University Hospital, Radiology, Besançon, France

Background: Lesions detected by magnetic resonance imaging (MRI) of the sacroiliac joints are critical to the diagnosis of non-radiographic axial spondyloarthritis (1). However, some lesions, such as bone marrow edema (BME), usually observed in patients with spondyloarthritis may be encountered in other conditions. BME have been described in patients with nonspecific back pain, healthy subjects, women with postpartum and in athletes (2). Moreover, it has recently been shown that structural lesions of the sacroiliac joint, such as erosions and fat metaplasia, may be present in healthy subjects (3).

Objectives: To evaluate and compare the frequency and location of lesions (BME, subchondral condensation, fat metaplasia, erosions and ankylosis) on MRIs of the sacroiliac joint of healthy individuals and patients with spondyloarthritis.

Methods: This is a retrospective study conducted at the University Hospital of Besançon including 200 patients, each having received an MRI of the sacroiliac joints in coronal section and in $\mathrm{T} 1$ and Semicoronal short tau inversion recovery sequences. Two experienced readers evaluated the whole set of images to detect erosions, subchondral condensation, fat metaplasia, BME and ankylosis according to the definitions established by the Assessment of SpondyloArthritis MRI working group. We subdivided a sacroiliac joint into three segments, upper, medium and lower along the cranio-caudal axis. Within the middle segment, we retained 3 portions: anterior, intermediate, posterior along the ventro-dorsal axis. Overall, one sacroiliac joint contained five quadrants on the iliac side and five quadrants on the sacral side.

Results: Collected MRI of 200 patients (62\% female), 96 patients had spondyloarthritis (mean age $37.4 \pm 11.8$ years, $48 \% \mathrm{HLA}-\mathrm{B} 27+$ ), 104 subjects were unaffected by the disease (mean age $39.9 \pm 11.6$ years, $11 \% \mathrm{HLA}-\mathrm{B} 27+$ ). Of the 96 spondyloarthritis patients, $62(65 \%)$ had inflammatory buttock pain compared to $26(25 \%)$ in the group without spondyloarthritis. BME was seen in $62(65 \%)$ patients with spondyloarthritis mainly in the iliac quadrant of the intermediate middle segment and in 21 (20\%) patients without spondyloarthritis predominantly in the antero-middle quadrant. There were equal BME in women and men with spondyloarthritis. Subchondral condensation occurred in $45 \%$ of patients without spondyloarthritis, mostly in the antero-middle quadrant and in $36 \%$ of patients with spondyloarthritis. Fat metaplasia was present in $35 \%$ of spondyloarthritis patients and in $23 \%$ of control patients. Erosions were seen in $31 \%$ of healthy patients and in $61 \%$ of patients with spondyloarthritis.

Conclusion: In this large retrospective cohort, we observed a significant frequency of inflammatory but also structural lesions on MRls of sacroiliacs joints from healthy patients, which could lead to the misdiagnosis of spondyloarthritis. Fine identification of the location of these lesions is crucial to avoid erroneous diagnosis.

References:

[1] Maksymowych WP. The role of imaging in the diagnosis and management of axial spondyloarthritis. Nat Rev Rheumatol. nov 2019;15(11):657-72.
[2] de Winter J, de Hooge $M$, van de Sande $M$, de Jong $H$, van Hoeven $L$, de Koning A, et al. Magnetic Resonance Imaging of the Sacroiliac Joints Indicating Sacroiliitis According to the Assessment of SpondyloArthritis international Society Definition in Healthy Individuals, Runners, and Women With Postpartum Back Pain. Arthritis Rheumatol Hoboken Nj. juill 2018;70(7):1042-8

[3] Seven S, Østergaard M, Morsel-Carlsen L, Sørensen IJ, Bonde B, Thamsborg G, et al. Magnetic Resonance Imaging of Lesions in the Sacroiliac Joints for Differentiation of Patients With Axial Spondyloarthritis From Control Subjects With or Without Pelvic or Buttock Pain: A Prospective, Cross-Sectional Study of 204 Participants. Arthritis Rheumatol. 1 déc 2019;71(12):2034-46.

Disclosure of Interests: None declared

DOI: 10.1136/annrheumdis-2020-eular.4202

\section{THU0528 NAILFOLD VIDEOCAPILLAROSCOPY REPORTING IN CLINICAL RESEARCH: INTERNATIONAL DELPHI BASED CONSENSUS}

F. Ingegnoli $^{1,2}$, T. Schioppo ${ }^{1,2}$, A. Herrick $^{3}$, A. Sulli ${ }^{4}$, F. Bartoli ${ }^{1,2}$, N. Ughi ${ }^{1}$ J. Pauling ${ }^{5}$, M. Cutolo ${ }^{4}$, V. Smith ${ }^{6}$ on behalf of EULAR Study Group on Microcirculation in Rheumatic Diseases and the Scleroderma Clinical Trials Consortium. ${ }^{1}$ G Pini Hospital, Clinical Rheumatology Unit, Milan, Italy; ${ }^{2}$ Università degli Studi di Milano, Milan, Italy; ${ }^{3}$ Division of Musculoskeletal \& Dermatological Sciences, The University of Manchester, Manchester, United Kingdom; ${ }^{4}$ Research Laboratory, Academic Division of Clinical Rheumatology, University of Genoa, Genoa, Italy; ${ }^{5}$ University of Bath, Bath, United Kingdom; ${ }^{6}$ Department of Rheumatology, Ghent University Hospital, Ghent, Belgium

Background: Nailfold capillaroscopy (NVC), a non-invasive technique to assess microcirculation, is increasingly being incorporated into rheumatology routine clinical practice. Currently, the degree of description of NVC methods varies amongst research studies, making interpretation and comparison between studies challenging. In this field, an unmet need is the standardization of items to be reported in research studies using NVC.

Objectives: To perform a Delphi consensus on minimum reporting standards in methodology for clinical research, based on the items derived from a systematic review focused on this topic.

Methods: The systematic review of the literature on NVC methodology relating to rheumatic diseases was performed according to PRISMA guidelines (PROSPERO CRD42018104660) to July $22^{\text {nd }} 2018$ using MEDLINE, Embase, Scopus. Then, a three-step web-based Delphi consensus was performed in between members of the EULAR study group on microcirculation in rheumatic diseases and the Scleroderma Clinical Trials Consortium. Participants were asked to rate each item from 1 (not appropriate) to 9 (completely appropriate).

Results: In total, 3491 references were retrieved in the initial search strategy, 2862 were excluded as duplicates or after title/abstract screening. 632 articles were retrieved for full paper review of which 319 fulfilled the inclusion criteria. Regarding patient preparation before the exam, data were scarce: $38 \%$ reported acclimatization, $5 \%$ to avoid caffeine and smoking, $3 \%$ to wash hands and $2 \%$ to avoid manicure. Concerning the device description: $90 \%$ reported type of instrument, $77 \%$ brand/model, $72 \%$ magnification, $46 \%$ oil use, $40 \%$ room temperature and $35 \%$ software for image analysis. As regards to examination details: $76 \%$ which fingers examined, $75 \%$ number of fingers examined, $15 \%$ operator experience, $13 \%$ reason for finger exclusion, $9 \%$ number of images, $8 \%$ quality check of the images and $3 \%$ time spent for the exam. Then, a three-round Delphi consensus on the selected items was completed by 80 participants internationally, from 31 countries located in Australia, Asia, Europe, North and South America. Some items reached the agreement at the second round (85 participants), and other items were suggested as important to consider in a future research agenda (e.g. temperature for acclimatization, the impact of smoking, allergies at the application of the oil to the nailbed, significance of pericapillary edema, methods of reporting hemorrhages, ramified and giant capillaries). The final agreement results are reported below: 


\begin{tabular}{|c|c|c|c|c|}
\hline PATIENT PREPARATION & $1-3$ & $4-6$ & 7-9 & $\begin{array}{c}\text { Median } \\
\text { (rating 1-9) }\end{array}$ \\
\hline Patients should undergo a period of acclimatization & 4 & 8 & 73 & 8 \\
\hline Patients should be asked to remove nail polish prior to procedure & 10 & 14 & 61 & 9 \\
\hline $\begin{array}{l}\text { Patients should be asked to remove artificial or gel nails prior to } \\
\text { procedure }\end{array}$ & 9 & 13 & 63 & 9 \\
\hline Patients should be asked to avoid manicure prior to procedure & 0 & 10 & 75 & 9 \\
\hline Patients should be asked about their job and hobbies & 4 & 10 & 71 & 9 \\
\hline $\begin{array}{l}\text { Patients should be asked about their sport and physical activities (i.e. } \\
\text { outdoor/indoor activities) }\end{array}$ & 10 & 14 & 61 & 8 \\
\hline Patients should be asked about their dominant hand & 6 & 14 & 65 & 8 \\
\hline $\begin{array}{l}\text { Patients should be asked about specific medications (i.e. beta- } \\
\text { adrenergic blockers, vasodilators, anticoagulants and antihypertensive } \\
\text { drugs) and other agents with vasoactive effects (i.e. cannabis, cocaine, } \\
\text { amphetamines) }\end{array}$ & 2 & 6 & 77 & 9 \\
\hline Patients should be asked about their comorbidities & 5 & 3 & 77 & 9 \\
\hline $\begin{array}{l}\text { Patients should be asked about recent finger trauma, nail biting } \\
\text { (onychophagy) and/or habit of self-injuring the cuticles }\end{array}$ & 2 & 4 & 79 & 9 \\
\hline $\begin{array}{l}\text { Patients should be asked to provide a detailed description of digital } \\
\text { colour changes (to ascertain the diagnosis of Raynaud's phenomenon) }\end{array}$ & 2 & 9 & 74 & 9 \\
\hline Specify whether the exam is performed during a Raynaud's attack & 13 & 15 & 57 & 8 \\
\hline Patients should be asked about their age & 3 & 8 & 74 & 9 \\
\hline Patients should be asked about history of digital ulcers & 6 & 5 & 69 & 9 \\
\hline Capillaroscopy should not be performed during RP attack & 13 & 12 & 55 & 8 \\
\hline \multicolumn{5}{|l|}{ DEVICE DESCRIPTION } \\
\hline $\begin{array}{l}\text { The make and model of the nailfold capillaroscopy device should be } \\
\text { reported }\end{array}$ & 1 & 12 & 72 & 9 \\
\hline Details of magnification should be reported & 0 & 2 & 83 & 9 \\
\hline The use of automated grid should be reported & 0 & 10 & 75 & 8 \\
\hline The use of oil should be reported & 14 & 13 & 58 & 8 \\
\hline Details of computer software for image analysis should be reported & 8 & 11 & 66 & 9 \\
\hline \multicolumn{5}{|l|}{ EXAMINATION DETAILS } \\
\hline $\begin{array}{l}\text { Details of experience or qualification of personnel responsible for } \\
\text { image acquisition and interpretation should be reported }\end{array}$ & 9 & 16 & 60 & 8 \\
\hline $\begin{array}{l}\text { In case of more than one examiner, training for each examiner should } \\
\text { be specified }\end{array}$ & 10 & 15 & 60 & 8 \\
\hline The number of fingers examined should be reported & 1 & 0 & 84 & 9 \\
\hline It should be reported which fingers have been examined & 2 & 2 & 81 & 9 \\
\hline $\begin{array}{l}\text { Each finger should be analyzed and reported separately or together } \\
\text { based on the study design }\end{array}$ & 18 & 17 & 50 & 7 \\
\hline $\begin{array}{l}\text { Images of each finger should be coded, numbered and stored in order } \\
\text { to allow comparative/prospective studies }\end{array}$ & 2 & 14 & 69 & 8 \\
\hline Reasons for finger exclusion should be reported & 2 & 6 & 77 & 9 \\
\hline Number of images collected at each nailfold should be reported & 6 & 17 & 62 & 8 \\
\hline Details of image quality (and missing data) should be reported & 2 & 15 & 68 & 8 \\
\hline $\begin{array}{l}\text { Details of global condition of the hands (e.g. flexion contractures) } \\
\text { should be reported }\end{array}$ & 6 & 15 & 64 & 8 \\
\hline Details on image reading (e.g. blind reading) should be reported & 7 & 8 & 70 & 9 \\
\hline $\begin{array}{l}\text { Report the overall pattern (i.e. normal: stereotype normal and non- } \\
\text { specific abnormalities versus abnormal: scleroderma patterns }\end{array}$ & 1 & 8 & 76 & 9 \\
\hline $\begin{array}{l}\text { Report the validated scleroderma patterns (i.e. early, active, late or } \\
\text { scleroderma-like) }\end{array}$ & 0 & 8 & 77 & 9 \\
\hline
\end{tabular}

Conclusion: On the basis of the available literature the description of NVC methods was highly heterogeneous and individual published studies differed markedly. These practical suggestions developed using a Delphi process among international participants provide a guidance to improve and to standardize the NVC methodology in future clinical research studies.

Disclosure of Interests: Francesca Ingegnoli: None declared, Tommaso Schioppo: None declared, Ariane Herrick: None declared, Alberto Sulli Grant/research support from: Laboratori Baldacci, Francesca Bartoli: None declared, Nicola Ughi: None declared, John Pauling: None declared, Maurizio Cutolo Grant/ research support from: Bristol-Myers Squibb, Actelion, Celgene, Consultant of: Bristol-Myers Squibb, Speakers bureau: Sigma-Alpha, Vanessa Smith Grant/ research support from: The affiliated company received grants from Research Foundation - Flanders (FWO), Belgian Fund for Scientific Research in Rheumatic diseases (FWRO), Boehringer Ingelheim Pharma $\mathrm{GmbH} \& \mathrm{Co}$ and Janssen-Cilag NV, Consultant of: Boehringer-Ingelheim Pharma GmbH \& Co, Speakers bureau: Actelion Pharmaceuticals Ltd, Boehringer-Ingelheim Pharma $\mathrm{GmbH} \& \mathrm{Co}$ and UCB Biopharma Sprl

DOI: 10.1136/annrheumdis-2020-eular.2415

\section{THU0529 CAPILLAROSCOPIC ALTERATIONS IN PATIENTS WITH IDIOPATHIC INFLAMMATORY MYOPATHIES}

V. Kachkovska ${ }^{1}$, A. Kovchun ${ }^{1}$, E. Prystupa ${ }^{2}$, L. Prystupa ${ }^{1} .{ }^{1}$ Sumy State University, Sumy, Ukraine; ${ }^{2}$ Iviv State University of Physical Culture, Lviv, Ukraine

Background: Nailfold capillaroscopy (NFC) is a useful, noninvasive, widely available diagnostic tool in rheumatology practice. We commonly use it to describe patterns of abnormalities in systemic sclerosis however we have enough data which proves NFC usefulness for monitoring idiopathic inflammatory myopathies (IIM) considering it as diagnostic tool, monitoring of disease activity and treatment efficiency. Despite evident clinical relevance of NFC in IIM patients we still do not have clear capillaroscopic images for IIM definition.

Objectives: That's why, the goal of our research was aimed to analyze capillaroscopic peculiarities among IIM patients and find possible associations with clinical and activity data.

Methods: 69 patients with IIM were examined and 47 IIM patients with capillaroscopic alterations were included in the study, 26 patients with dermatomyositis (DM) and 21 patients with polymyositis (PM) according to the Targoff Criteria (1997). NFC we performed using Dino-Lite CapillaryScope with 200 magnification. We assessed nailfold capillary density (NCD), presence of microhemorrhages, giant, dilated and ramified capillaries, scleroderma patterns (defined as an early, active or late pattern) and neovascular pattern (defined as an active and late scleroderma patterns). To asses disease activity we use Manual Muscle Testing 8 (MMT8), Health Assessment Questionnaire (HAQ), Myositis Disease Activity Assessment Tool (MDAAT), Cutaneous Dermatomyositis Disease Area and Severity Index (CDASI), physician's VAS, patient's VAS, serum muscle enzymes levels. We divided patients into 4 groups: $1^{\text {st }}$ group -17 DM patients with active disease ( 8 of them with newly onset disease), $2^{\text {nd }}$ group included 9 DM patients with inactive disease, $3^{\text {rd }}$ group -11 PM patients with active disease ( 5 of them with newly onset disease) and $4^{\text {th }}$ group included 10 PM patients with inactive disease.

Results: The most common finding was low NCD, $70 \%$ of all patients had NCD lower than 6 per $1 \mathrm{~mm}$. NCD for the $1^{\text {st }}$ group was $4,4 \pm 1,12,2^{\text {nd }}$ group $-6,0 \pm 1,0$ $3^{\text {rd }}$ group $-5,8 \pm 1,1,4^{\text {th }}$ group $-9,2 \pm 2,1(F=26,27, p<0,001)$. Hemorrhages were significantly more common among DM patients and active disease and were observed among 47,1\% ( $p=0,036, x 2=8,574)$ with no significant difference with regard to the disease onset. Analyzing scleroderma patterns, among $1^{\text {st }}$ group of patients $-17,6 \%$ had early, $47,1 \%$ - active, $35,3 \%$ - late pattern, in the $2^{\text {nd }}$ group $-66,7 \%$ had early pattern, in the $3^{\text {rd }}$ group $-27,3 \%$ patients with early and $18,2 \%$ with active pattern and in the $4^{\text {th }}$ group $-50 \%$ of patients presented with early pattern $(p=0,001, x 2=31,87)$. Neovascular pattern was found significantly more often among patients with active DM $(p=0,001)$ with no regard to the disease onset. No statistically significant difference in giant and ramified capillaries distribution was found.

Conclusion: According to our results, we can admit that the most common capillaroscopic finding was decreased NCD, which were significantly lower among patients with active DM, the same as microhemorrhages and neovascular scleroderma pattern. This data suggests that NCD, microhemorrhages and neovascular scleroderma pattern could be consider as biomarkers of DM activity but not PM, therefore more detailed research with larger numbers of patients are required.

Disclosure of Interests: None declared

DOI: 10.1136/annrheumdis-2020-eular.3139

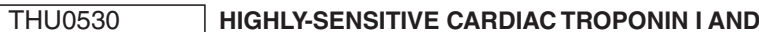 BETA-2-GLYCOPROTEIN-I IGA ANTIBODIES INFORM THE UTILITY OF SCREENING AND FOLLOW-UP NON-INVASIVE CORONARY ATHEROSCLEROSIS EVALUATION AND OPTIMIZE CARDIOVASCULAR RISK ASSESSMENT IN RHEUMATOID ARTHRITIS}

G. Karpouzas ${ }^{1}$, S. Ormseth ${ }^{1}$, E. Hernandez ${ }^{1}$, M. Budoff ${ }^{1} .{ }^{1}$ Lundquist Institute of Biomedical Innovation, Torrance, United States of America

Background: Occult coronary atherosclerosis burden predicts mid-term cardio vascular disease (CVD) events in rheumatoid arthritis (RA) above and beyond Framingham D'Agostino cardiac risk score (FRS-DA). Highly-sensitive cardiac troponin I (hs-cTnl) levels in blood associate with coronary plaque burden and event risk in RA. Moreover, IgA antibodies against beta2-glycoprotein-1 (a-b2G$\mathrm{PI}-\lg \mathrm{A}$ )- an atherosclerotic plaque antigen- in RA promote coronary plaque progression and moderate the effect of inflammation on CVD events. It is currently unclear when to recommend a screening, non-invasive coronary atherosclerosis evaluation in asymptomatic RA patients and whether such an assessment should be repeated.

Objectives: To explore whether either biomarker alone or their combination improved prediction of plaque presence on an initial coronary CT angiogram (CCTA) beyond FRS-DA score; to evaluate whether either biomarker predicted progression to extensive or obstructive plaque on a follow-up evaluation.

Methods: One hundred fifty RA patients underwent a baseline CCTA; 101 had repeat evaluation within $6.9 \pm 0.3$ years. $\mathrm{Hs}-\mathrm{cTnl}$ and a-b2GPI-IgA were assessed at baseline; the latter were confirmed 12 weeks later, if positive. Lesions render ing greater than $50 \%$ luminal stenosis were considered obstructive. Extensive plaque was defined as $>5$ coronary segments with plaque, or stenosis score $>5$ or coronary artery calcium score $(C A C)>100$. The diagnostic accuracy of FRS-DA alone vs. with hs-cTnl or a-b2GPI-IgA individually or combined for plaque or $\mathrm{CAC}$ at baseline was evaluated as area under the curve (AUC). Improvement 